\title{
Postsynaptic $\alpha$-Neurotoxin Gene of the Spitting Cobra, Naja naja sputatrix: Structure, Organization, and Phylogenetic Analysis
}

\author{
Fatemeh Afifiyan, Arunmoziarasi Armugam, Chee Hong Tan, \\ Ponnampalam Gopalakrishnakone, and Kandiah Jeyaseelan ${ }^{1}$ \\ Department of Biochemistry, Faculty of Medicine, National University of Singapore, 119260 Singapore
}

\begin{abstract}
The venom of the spitting cobra, Naja naja sputatrix contains highly potent $\alpha$-neurotoxins (NTXs) in addition to phospholipase $\mathrm{A}_{2}\left(\mathrm{PLA}_{2}\right)$ and cardiotoxin (CTX). In this study, we report the complete characterization of three genes that are responsible for the synthesis of three isoforms of $\alpha$-NTX in the venom of a single spitting cobra. DNA amplification by long-distance polymerase chain reaction (LD-PCR) and genome walking have provided information on the gene structure including their promoter and $5^{\prime}$ and $3^{\prime}$ UTRs. Each NTX isoform is $\sim 4 \mathrm{~kb}$ in size and contains three exons and two introns. The sequence homology among these isoforms was found to be $99 \%$. Two possible transcription sites were identified by primer extension analysis and they corresponded to the adenine (A) nucleotide at positions +1 and -45 . The promoter also contains two TATA boxes and a CCAAT box. Putative binding sites for transcriptional factors AP-2 and GATA are also present. The high percentage of similarity observed among the NTX gene isoforms of $N$. n. sputatrix as well as with the $\alpha$-NTX and $\kappa-N T X$ genes from other land snakes suggests that the NTX gene has probably evolved from a common ancestral gene.
\end{abstract}

[The genomic DNA sequences reported in this paper have been submitted to GenBank databases under accession nos. AF096999 to AF097001.]

Snake venom contains various toxic proteins among which the most toxic are the postsynaptic neurotoxins (NTXs) or $\alpha$-NTXs. Fractionation of cobra venom showed that the $\alpha$-NTXs constitute only $\sim 3 \%$ by weight of crude venom (Tan 1983). These potent toxins bind specifically to the nicotinic acetylcholine receptor (nAChR) in the postsynaptic membrane of skeletal muscles, thus preventing the binding of the chemical neurotransmitter acetylcholine and thereby blocking the excitation of muscles. This block at the neuromuscular junction leads to flaccid paralysis and causes death by respiratory failure (Chang 1979). The molecular structure and function of postsynaptic NTXs have been thoroughly investigated (Low et al. 1976; Tsernoglou and Petsko 1976; Dufton and Hider 1983).

To date, the amino acid sequences of 52 short $\alpha$-NTXs have been reported in the protein databases. The existence of various isoforms of short $\alpha$-NTXs from sea snakes, Laticauda semifasciata (Tamiya et al. 1985; Obara et al. 1989; Fuse et al. 1990) and Aipysurus laevis, (Ducancel 1990) was revealed through cDNA cloning. Recently, we have cloned and expressed four cDNAs encoding four short $\alpha$-NTXs isoforms (NTX1, NTX2, NTX3, and NTX4) from the Malayan spitting cobra Naja naja sputatrix (Afifiyan et al. 1998). The nucleotide sequences of these NTX cDNAs were found to be highly homologous ( $99 \%$ ) to each other.

\footnotetext{
'Corresponding author.
}

E-MAIL bchjeya@nus.edu.sg; FAX +65-779 1453.
The genes encoding erabutoxin c from the sea snake L. semifasciata (Fuse et al. 1990) and cobrotoxin and cobrotoxin $\mathrm{b}$ from the Taiwan cobra Naja naja atra (Chang et al. 1997a,b) have been described. In this report we present for the first time the cloning and characterization of three isoforms of the NTX gene from the genome of a single spitting cobra, $N$. $n$. sputatrix. These genes are found to correspond to the three NTX cDNAs identified previously in N. $n$. sputatrix (Afifiyan et al. 1998).

\section{RESULTS}

\section{Genomic PCR and DNA Sequencing}

The strategy used for genomic and genome-walking PCR analysis, location of primers, and organization of the NTX gene is shown in Figure 1A. PCR amplification of N. n. sputatrix genomic DNA was carried out initially by use of two sets of primers (X133, X153 and X91, $X 92)$. These primers were designed on the basis of the highly conserved regions of the NTX cDNAs. The primers $X 133$ and $X 91$ are sense primers, which anneal to exon 1 (leader sequence) and the $5^{\prime}$ end of exon 2 , respectively. The primers X153 and X92 are antisense primers that anneal to the $3^{\prime}$ end of exon 3.

Analysis of the genomic PCR products on 1\% agarose gel electrophoresis revealed two bands, $742 \mathrm{bp}$ and $2.1 \mathrm{~kb}$ for primers $X 91, X 92$ and $X 133, X 153$, respectively (Fig. 1B, lanes 2,3). PCR amplification of NTX cDNA clones with the above combination of primers 
A

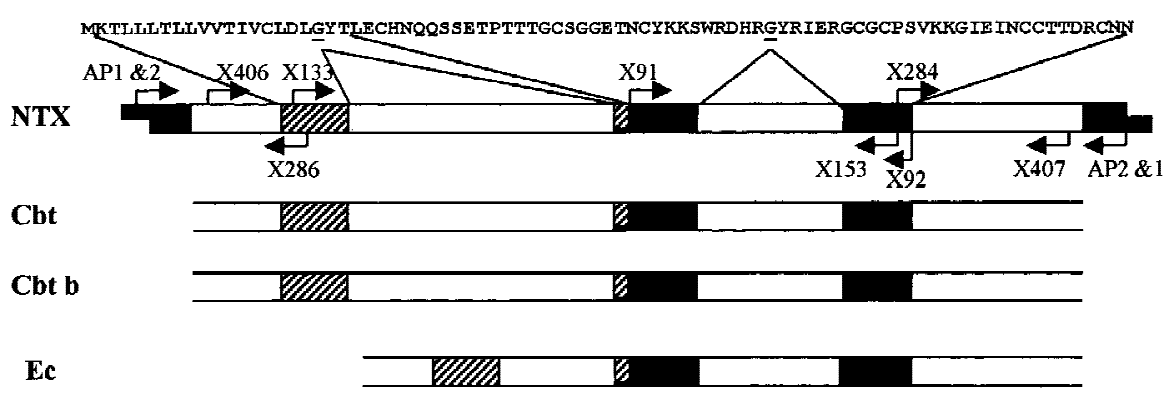

B
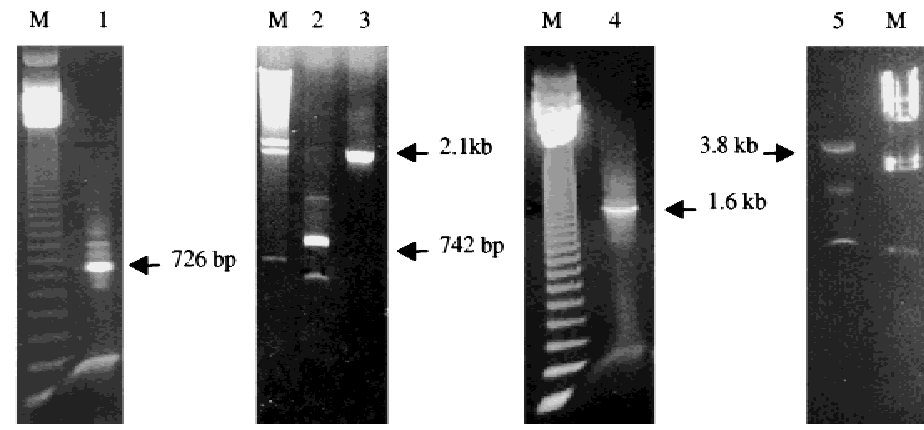

Figure 1 Strategies used for PCR and genome walking. $(A)$ Locations of primers used to amplify the NTX gene by PCR and comparison of the gene organization of NTX (NTX; N. n. sputatrix), cobrotoxins (Cbt and Cbt $b ; N$. $n$. atra) and erabutoxin $c(E c ;$ L. semifasciata). (Solid and open boxes) Exons and introns, respectively. The amino acids corresponding to each exon are also indicated. (B) Agarose gel electrophoresis of PCR products from upstream (lane 1) and downstream (lane 4) of the NTX gene generated by genome walking. (Lanes 2,3) Genomic fragments of $N T X$ gene containing the coding region for signal peptide and matured toxin respectively. (Lane 5) Amplification of the complete NTX gene(s) from N. $n$. sputatrix.

them, three different clones (NTX1, NTX2, and NTX4) encoding three isoforms of the short $\alpha$-NTX (ETS, QAS, and QAG) were identified. These clones correspond to three of the four cDNAs of NTX (NTX1, NTX2, and NTX4) that were characterized previously (Afifiyan et al. 1998). All of the 21 clones shared identical 5' and 3' sequences. The average frequencies of finding genomic clones corresponding to NTX1, NTX2 and NTX4 were $\sim 33 \%$. Each NTX gene was found to contain two introns of $\sim 1.2$ and $0.5 \mathrm{~kb}$ (Fig. 2). The intron sequences among the NTX isoforms appear identical.

The first intron occurs within the NTX leader sequence region between nucleotides 84 and 1288 at a position between ${ }^{-4}$ Leu and ${ }^{-3}$ Gly of the signal peptide (Figs. 1A and 2). The second intron divides the coding region of the gene between nucleotides 1395 and 1949. This intron interrupts the central loop sequence of the mature toxin between ${ }^{33} \mathrm{Arg}$ and ${ }^{34} \mathrm{Gly}$.

gave a band of $\sim 200 \mathrm{bp}$ (data not shown). These results suggest the presence of introns of $\sim 1.8 \mathrm{~kb}$ in the NTX gene. In a separate experiment, a 726-bp PCR product corresponding to the $5^{\prime}$ end of the gene was obtained from the DraI genome walker library (Fig 1B, lane 1) by use of a universal adapter primer and gene-specific antisense primer (X286). Likewise, a 1603-bp 3' end of the NTX gene was amplified from the DraI library (Fig. $1 \mathrm{~B}$; lane 4) by a combination of adapter primer (AP2) and another gene-specific sense primer (X284). The nucleotide sequences of all of the PCR products were determined, and a complete sequence of the NTX gene was deduced. Two gene-specific primers, X406 (sense: 5'-GAAGTCGGGGAATGGTTGGTC-3') and X407 (antisense: $5^{\prime}$-TTCTTGGGGCTTGTTAGTTTAGTT-3') from the $5^{\prime}$ and $3^{\prime}$ ends of the gene were synthesized and the NTX gene was amplified by sequential PCR with the $5^{\prime}$ fragment (726 bp), the mid-region of the gene (2100 bp), and the 3 ' fragment (1603 bp). The NTX gene was also amplified by direct PCR with $N$. $n$. sputatrix genomic DNA as a template. In both PCR reactions, we obtained a 3.8-kb product (Fig. 1B, lane 5). These PCR products were subcloned into the pT-Adv vector and a total of 21 genomic clones were sequenced. Among
This is similar to what has been observed with other NTX genes (Ec and Cbt), in which the exons are separated from the introns at the same positions. The NTX gene is composed of three exons. The first exon encodes the 5' UTR and most of the leader sequence. The second exon consists of 108 bases and encodes the remaining part of the leader sequence and 33 of 62 amino acid residues of the NTX protein and exon 3 represents the coding region of 29 amino acid residues of NTX and $200 \mathrm{bp}$ of $3^{\prime}$ UTR.

Nucleotide and deduced amino acid sequence comparison among the three NTX gene isoforms shows that the introns and two exons, exon 1 and exon 3, are highly conserved, whereas the second exon, which encodes the amino-terminal half of mature NTXs, shows nucleotide variation (Fig. 2). The nucleotide variation thus leads to variation in the amino acids being encoded, resulting in the identification of three isoforms of the NTX gene encoding three types of NTXs in the venom of a single spitting cobra.

\section{Transcription Initiation Site of the NTX Gene}

The transcription initiation site (TIS) was determined by primer extension with reverse transcriptase and ${ }^{33} \mathrm{P}-$ 


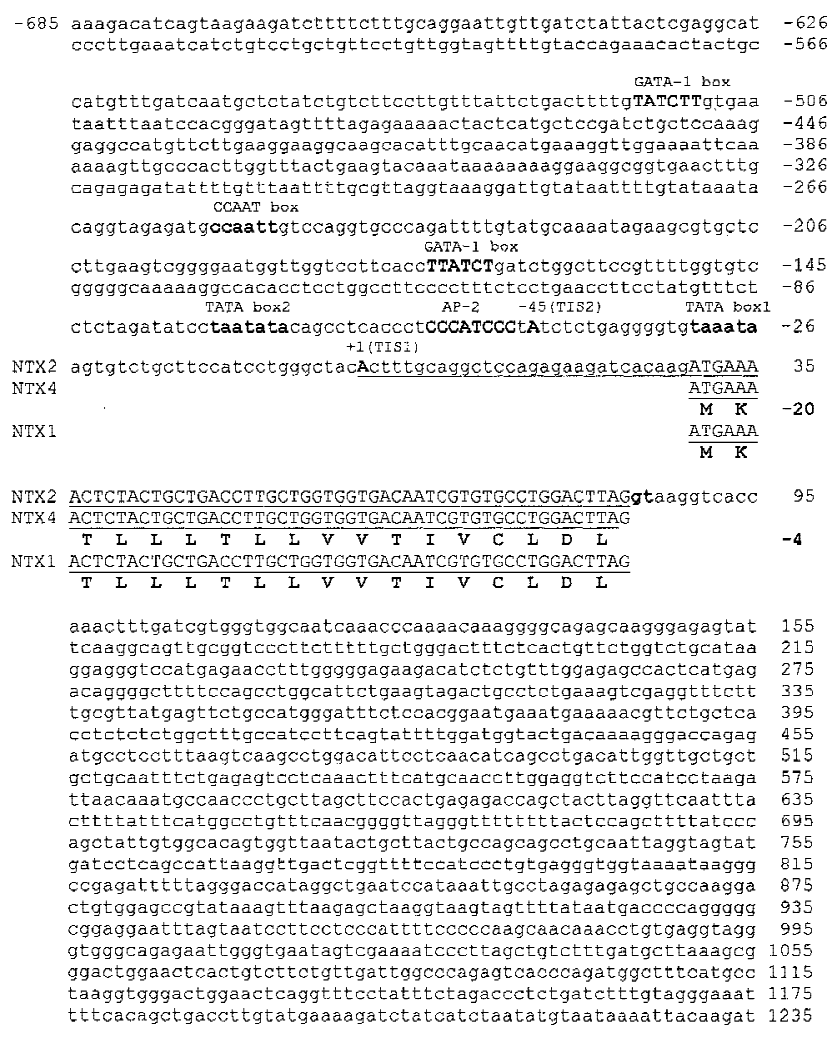

Figure 2 Complete nucleotide sequences of $N T X$ genes, NTX1, NTX2, and NTX4, including the introns and 5 '- and 3 '-flanking regions. Only one intron sequence is included, as all three genes are identical. The exon sequences are in uppercase letters. The deduced amino acid sequences are presented as one-letter code below the codons and are numbered separately. The transcriptional elements are in uppercase letters and boldface. The important elements in the $3^{\prime}$ end of the NTX gene such as the AATAAA and TGTTTG sequences, are in boldface italics.

labeled primer $X 286$, which is complementary to the $5^{\prime}$ end of the toxin mRNA sequence. Two major products arising from A's in ACTTT (TIS1) and ATCTC (TIS2) at positions +1 and -45 , respectively, have been observed (data not shown). The location of TIS1 closely resembled the TIS reported for erabutoxin c and cobrotoxin by Fuse et al. (1990) and Chang et al. (1997a), respectively. The presence of two putative TATA-box motifs at -31 and -73 bp in the NTX gene of N. $n$. sputatrix supports our observation of two TISs. However, only one putative CAAT element could be seen in the promoter sequence.

\section{Genomic Southern Blot Analysis}

Southern blot analysis of the N. n. sputatrix genome

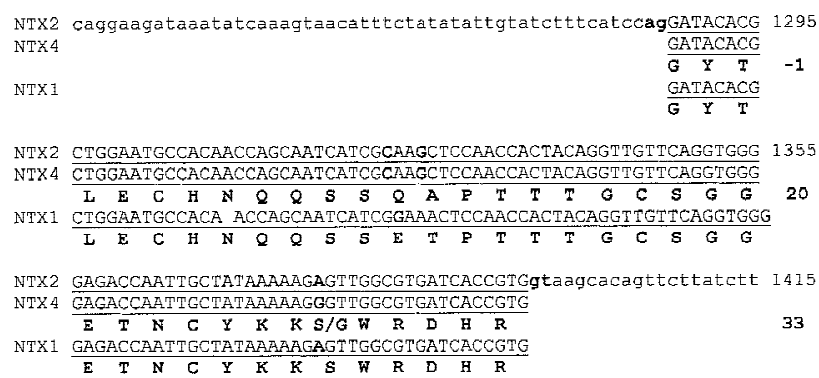

ctcgcacagctttttttcttcttgaacccagactagagctccagaatgcatctgagaact 1475 ggaggteatgtaagacetgtetgtgectgcctgggttcccctgaggtcacgtectgttg 1535 ccggacactctaagcaatgcaaggaaaggggggtettggactggggtgecceatcttct 1595 cagcaacagcccastctggagggggaaacctettcagagaaagaggaagggaatgctg 1655 ggagagctgcacggtttgttctggaattgagggaättggatgaagaecatgaaaggtgc 1715 Catccaggaaaggtgccattgcccttgagtcatgtaacaatacaggctttcccoaat 1775 ctcttcttcattcatttactctgagtttaagtagaggaggaggtctgcettectactg 1835
ggaggggatgcatgaatgtgttcagtgtggtttaccatttggttcagcaatagccacagg 1895 NTX2 tctgttctttggtattttttaaaaatcattctgctttgtgttttcttcacagGATATAG 1955 NTX

NTX1 GATATAG GATATAG

NTX2 AATCGAGAGGGGATGTGGTTGCCCTTCAGTGARGAAAGGCATTGAAATMAACTGTTGCAC 2015 NTX4 AATCGAGAGGGGATGTGGTTGCCTTCAGTGAAGAAAGGCATTGAAATTAACTGTTGCAC

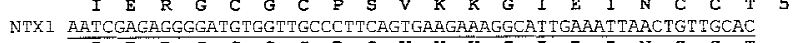

NTTX2 AACCGACCGCTGCAACAATTAGCtctcegagtggctaaattcettgagttttgetctcat 2075 NTX4 AACCGRCCGCTGCAACAATIAG

62

NTX1 AACCGACCGCTGCAACAATTAG

ccatcatggaccatccttgaaaatttatgcttgtggcetttagcaccagatggtecatet 2135 ccctgetgtctttgacacctcaacatctttcocttttctcttgctctgtaagattcett 2195 ctgctagttctgtaatttgagaatcaAATAAAattcagcattcaattcaat TGMTrTGat 2255

tttttaatccctccacaaaacatcccttcătaaaacceccaggtagagagtctttcce 2315 cggttttcatcaggaagtgatgctgggatgtgcaggattaggtccaatccctgttgaatc 2375 atgccttgtatagcctaatggggtaataacettagattcagacagggtaaagaaagagga 2435 gaaacccacaactgagtettcctcaqtaaaacctcaaacttcaaagcctccctttcttc 2495 tetctggggaaagctgaggggaagaggaagatgccttgaàcagaggagggggatttggg 2555 ctgaaggatggcaggcetcttctccatcacgcccacctgaaagaagaaacatcttgattc 2615 aacagttgactttgcaggetettetcaagcttctcaatcctgggttcaaggtatggcgg 2675 ttatacctggacatcggggcttcactggcctgatctttcetcactgcattgggtaaactg 2735 gggtgaagct tcactggttttcctctttgcagcaggtagaccagcccgaagcttccctga 2795 cttgatcttectcectgcattgggtaaactgggctgaagcgacaccagtagactgggat 2855 ggccggattaaacccattgcgggccttgagtttgacaccctgoactacactgatttggt 2915 cettcctccaaaagcatattggactccaatacatactcccttaaataatgataaaa 2975 cacactttaaatttgaaccaaagtatetttggtggtttattaccauttaaaaagcatat 3035 tggactcazatacatacttccttaggataaatgataaaacagcacgtagatttgaaecca 3095 gaggtatttttggtgggtatattaccagatcagcatgacaaaggggaacgtatttaatt 3155 ttacatgtactầcgggagccagaatggtgtttgcacagggatggaaaaagggagagatc 3215 cctgcagagggaaatcttattaaaaaaatattagaa tgtgetgagatggacagattaaca 3275 cttaaataaaagacaagggaggaacaggatactttttanatgggacttgttttaccca 3335 atggctaattaaacagggaatagaggttacaaaccaaaagattaaaaatagaataaaaa 3395 tttctgattgataattttcaagattgataaactaattgtattatcactttgggatttt 3455 att tattatttatttattaatgggact tgtatgccgccccatctccgaagactcggggtg 3515 gctcacagttaaaagacaataacaataaatagttaaaagagattaactaadctaca 3575 gccccaagaaaaaaatacaaattt.

with cDNA encoding the NTX (NTX2) as a probe, showed three bands for BamHI, EcoRI, HindIII, and PstI digests of genomic DNA (Fig. 3), indicating the presence of at least three isoforms of the NTX genes in the N. n. sputatrix genome.

\section{Phylogenetic Analysis}

Gene sequences of known $\alpha$-NTXs and cardiotoxins (CTXs) as well as $\kappa$-NTXs were aligned with a DNASIS software package. The noncoding DNA regions have been found to be more highly conserved than the coding regions. The phylogenetic relationships were analyzed on the basis of combined coding and noncoding regions (exons and introns, Fig. 4). This analysis shows that the $\kappa$-NTX genes are more conserved than those 


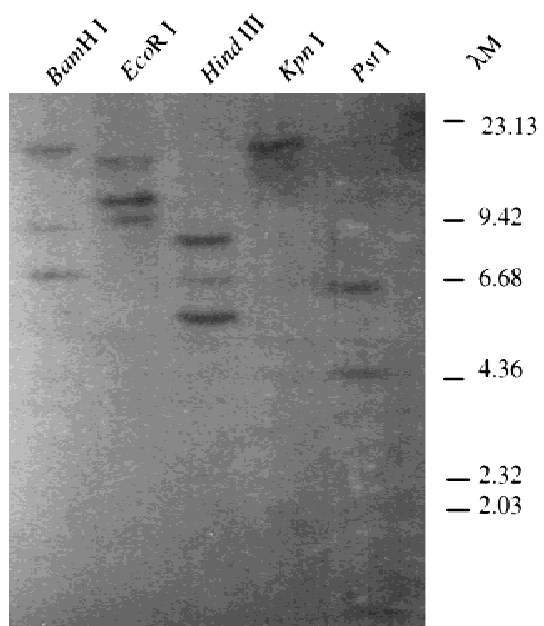

Figure 3 Southern blot analysis. Genomic DNA was digested with five restriction enzymes, and fragments were resolved on $0.8 \%$ agarose gels and blotted onto a nitrocellulose membrane. The NTX CDNA was used as probe.

encoding CTXs or $\alpha$-NTXs. In this analysis, NTXs, CTXs, and $\kappa-N T X s$ formed three divergent groups with NTX retaining its properties as the primitive form of toxin.

\section{DISCUSSION}

\section{Gene Structure of Short $\alpha$-NTX from N. n. sputatrix}

The gene encoding N. $n$. sputatrix NTXs consists of three exons and two introns (Fig. 2). The first exon contains the transcription initiation site, $5^{\prime}$ UTR and most of the signal peptide-coding gene sequence. This exon is interrupted by a 1203-bp intron 1, which segments the signal peptide into two regions. The second exon encodes three residues of leader sequence and the amino-terminal half of the mature NTX and is interrupted by intron 2 of $553 \mathrm{bp}$. The carboxy-terminal half of the mature NTX and 3' UTR are encoded by exon 3 . The intron-exon junctions that are typical of donor and acceptor splice site have followed the GT/AG rule (Breathnach and Chambon 1981; Iida and Sasaki 1983) in which the introns begin with GT and end with AG. The 3' and $5^{\prime}$ splice site of both introns are AT- and CT-rich except for the $5^{\prime}$ splice site of intron 1 , which contains $45 \%$ pyrimidines. This is consistent with the structure of introns in many other species, which are AT-rich (Csank et al. 1990).

The results of our study confirmed the presence of three isoforms of the short $\alpha-N T X$ in the genome of the single N. $n$. sputatrix. This is supported further by the Southern blot analysis of the liver genomic DNA with a NTX2 cDNA probe (Fig. 3). Previously we described the existence of four isoforms of short $\alpha$-NTX (NTX1, NTX2,
NTX3, and NTX4) from this snake (Afifiyan et al. 1998). These cDNA clones were obtained from 10 independent RT-PCR reactions with RNA isolated from eight snakes. However, the genomic clones used in this study were obtained from DNA isolated from a single snake. Therefore, it is probable that one or more of the snakes used in our previous study possessed a variation in one of the three genes to produce the fourth isoform of mRNA (NTX3).

The ATG codon at position 30 in Figure 2 could be the translation initiation codon as there is a nucleotide, $\mathrm{A}$ at the -3 position upstream and +4 position downstream of the ATG codon. This has been found in the mRNA of higher eukaryotes, which have purine nucleotides, most often an $\mathrm{A}$, at -3 position and an $\mathrm{A}$ or $\mathrm{G}$ at +4 position (Kozak 1986,1987).

cDNA cloning has shown the existence of at least three types of NTX mRNAs in a sea snake, L. semifasciata (erabutoxins a, b, and c). The genes encoding erabutoxin precursors also have been predicted (Tamiya et al. 1992) to be present as multicopy genes in L. semifasciata. The present study confirms for the first time the existence of three such isoforms of NTX genes and in this case, in the land snake N. n. sputatrix. The variations seen among these NTX isoforms can be traced to nucleotide substitutions in their second exon. This strongly suggests that the mRNAs encoding these NTXs are transcribed from independent genes that may have evolved by directional mutation (accelerated mutation). The mutations in these genes have been found to be single-base substitutions involving the first base of the codons.

The translation termination codon of the NTX genes is assigned to the codon TAG at position 2037 of Figure 2. The 3 ' end of the NTX gene contains a polyadenylation signal AATAAA at positions 2222-2227. Downstream of exon 3 (nucleotides 2247-2253) a sequence TGTTTTG can be identified. This sequence is similar to a consensus YGTGTTYY sequence that has

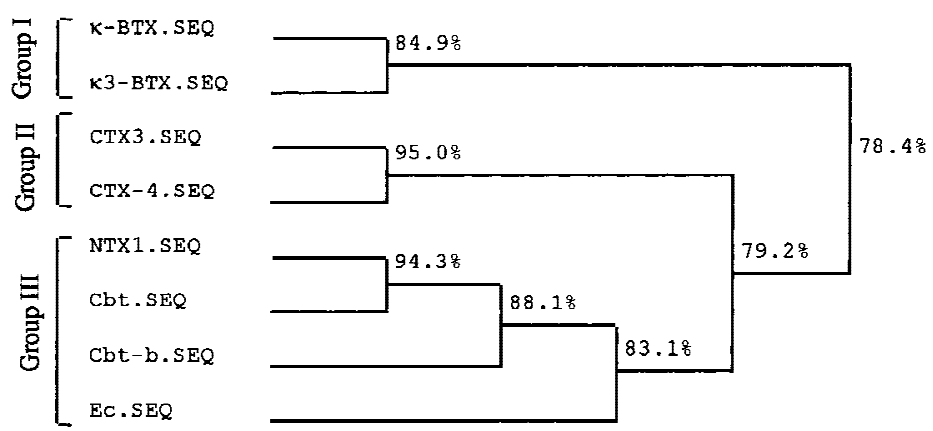

Figure 4 Phylogenetic analysis of snake toxins. A cladogram constructed for phylogenetic analysis with DNASIS software package is shown. The abbreviations used for $\alpha$-NTXs are the same as in Fig. 1. $\kappa-B T X$ and $\kappa_{3}-B T X$ are bungarotoxins from Bungarus multicinctus (accession nos: Y11768 and Y11769). (CTX3) The CTX from N. n. sputatrix (accession no. AF064096); (CTX-4) The CTX from N. n. atra (GenBank accession no. Y12493). 
been assumed to be functionally important among mammalian genes (Gil and Proudfoot 1984; McLauchlan et al. 1985).

\section{Putative Regulatory Sequence Elements of the Promoter Region}

The result of our primer extension showed that there are two possible sites for transcription initiation. The presence of multiple transcription sites are common in eukaryotic genes that are highly regulated at the level of transcription initiation (Kozak 1991). Multiple transcription sites in snake toxin genes in particular, and in animal toxin genes in general, were reported previously by our laboratory (Gendeh et al. 1997; Latchumanan et al. 1998). The presence of two TISs may result in the synthesis of a long and short $5^{\prime}$ UTR from the exon 1 of the NTX gene. The length of the 5' UTR may influence mRNA stability and/or translation efficiency. Its existence may be necessary for the efficient initiation of transcription.

Two TATA boxes at positions -31 to -26 and -73 to -67 and a CCAAT box possibly contributed by tissue-specific expression (see below) at positions -253 to -248 relative to the transcription start site 1 have been identified in the $5^{\prime}$ upstream region of this gene.

The promoter also contained one AP-2-binding site (CCCTACCC) at positions -54 to -47 , which is known to act as both basal and second messengerinducible enhancers (Imagawa et al. 1987; Faisst and Meyer 1992). At positions -516 to -511 and -173 to -168 , two binding motifs for GATA- 1 transcription factors (TATCT) can be located. The GATA family is currently comprised of six members, GATA- 1 to GATA6 , which recognize the GATA motif (WGATAR). It has been suggested that the GATA motif may negatively control transcription (Imagawa et al. 1994). The promoter region does not show any SP1 site. The SP1 site (GGGCGG) is present in a variety of promoters and has been envisaged to play a role in constitutive gene expression (Latchman 1991).

It is well established that in most animal species, the main cause of death resulting from cobra venom poisoning is peripheral respiratory paralysis induced by the NTXs. However, it has been shown that the venom of the Malayan spitting cobra constitutes only $\sim 3 \%$ by weight of the crude venom compared with a less lethal polypeptide CTXs, $60 \%$ by weight of crude venom, (Tan 1982, 1983). This shows that the NTX gene, which is expressed specifically in the venom gland and at a lower $(1 / 20)$ level than the CTX gene, should possess some differences in its promoter. Comparison of NTX and CTX promoters shows the absence of transcription factor-binding motifs such as NFIL-6, C/EBP, NF-кB, and PuF that have been observed in CTX genes (Latchumanan et al. 1989). These elements are known to stimulate the transcription of the genes (Akira et al. 1990; Baeuerle 1991; Postel et al. 1993). Interestingly, the CTX gene promoter region does not contain any GATA elements. Therefore, the lower expression of the NTX gene compared with the CTX gene in the snakes may be due to the absence of enhancer elements and also to the existence of two negatively regulating GATA elements in its promoters. At present, it is not known whether these elements are functionally active. Further experiments are required to evaluate the significance of these transcription elements.

\section{Comparison of Intron-Exon Organization to Other Known Toxin Gene Structure}

Our studies showed the existence of three isoforms of short $\alpha$-NTXs in the venom of a single snake. Although the presence of isoforms of the NTX molecules in a single venom source and multiple types of NTX cDNAs in a venom gland had been reported (Tan 1992; Afifiyan et al. 1998), this is the first report that establishes the gene-protein relationship of NTX found particularly in the venom of a spitting cobra and perhaps in other snakes as well.

The exon-intron organization of the N. $n$. sputatrix $N T X$ gene is similar to that of the erabutoxin c from $L$. semifasciata, cobrotoxin, and cobrotoxin b from N. $n$. atra (Fig. 1A). The nucleotide sequence of the exons and introns of the NTX gene from N. n. sputatrix also revealed a significant similarity to those reported in GenBank databases ( $C b t, C b t b, E c, \kappa-B T X, \kappa_{3}-B T X$, CTX3, and CTX-4). In all cases, the intron sequences shared high homology to each other. The exon 1 sequences, which encode for signal peptides, are highly conserved (up to 98\%). Significant differences have been observed among the exons 2 and 3 of these toxins. The intron 1 of NTX from sea snake (erabutoxin c) has been found to be six-fold shorter in length (196 bp) than its land snake counterpart (1203 bp). However, the first $163 \mathrm{bp}$ of intron 1 in erabutoxin c shows up to $90 \%$ homology with the first $163 \mathrm{bp}$ of $N$. n. sputatrix NTX. The remaining $23 \mathrm{bp}$ of erabutoxin intron 1 is identical to the 3 ' end of $N$. n. sputatrix intron 1 (1174 bp-1203 bp). It is likely that the region 164 bp-1173 bp in intron 1 of $N$. $n$. sputatrix might have been acquired during evolution of the snake (Orgel and Crick 1980; Gilbert 1987; Dibb and Newman 1989; Rogers 1989). This region of intron 1 exhibits the structural hallmarks of small nucleolar RNAs (snoRNAs) as described by Maxwell and Fourneir (1995) and Chang and Hong (1997).

The presence of a short intron in Ec compared with other NTXs could be either explained by the relative lower position of the sea snake in the evolutionary tree or by the advantage through the results of a potentially higher rate of gene expression. 


\section{Evolutionary Relationship of Snake Toxins}

Evolutionary mechanisms have been suggested to account for genes in which noncoding regions are more highly conserved than coding regions (Nakashima et al. 1993, 1995; Moura-da-Silva et al. 1995); these involve gene duplication followed by accelerated evolution of the coding regions. This pattern of sequence conservation can be seen among NTXs, CTXs, and к-NTXs of the elapid family. Examination of nucleotide sequences revealed high similarity for noncoding DNA regions and more variability in the coding regions. Our phylogenetic analysis, which is based on combined coding and noncoding regions (introns and exons), confirms the existence of a common ancestor for all types of toxin genes. Structurally similar, but functionally diverse, CTX and NTX genes appear to evolve about the same time from the ancestral gene. The divergence among the CTXs, NTXs, and $\kappa-N T X$ suggests that these genes may have been evolved under adaptive pressure through a positive Darwinian selection process as proposed by Ohno et al. (1998).

The functions of the various isoforms of $\alpha$-NTX in the venom of N. n. sputatrix are still unknown. However, these isoforms are unique to the species, and we hope that further studies of their biochemical properties and functions will eventually provide a better insight into their physiological roles in vivo.

\section{METHODS}

\section{Isolation of Genomic DNA}

Frozen snake liver was pulverized into a fine powder in liquid nitrogen (Sambrook et al. 1989). The genomic DNA was extracted in the presence of SDS and proteinase $\mathrm{K}$ (Boehringer Mannheim) and purified with phenol/chloroform. DNA was precipitated with 2.5 volumes of $95 \%$ ethanol. The pellet was washed with $70 \%$ ethanol and resuspended in TE buffer (10 mm Tris- $\mathrm{HCl}$ at $\mathrm{pH} 8,1$ mm EDTA).

\section{Amplification of Genomic DNA}

Custom-designed oligonucleotide primers based on the sequence of the highly conserved regions in the structural gene of $N$. $n$. sputatrix cDNA were supplied by Oswell DNA Service (UK).

The sense primers were X133, 5'-TCCAGAAAAGATCGCAAGATG-3' and X91, 5'-CTGGAATGCCACGACCAGCA-3' and antisense primers were X92, 5' - TTATCAGTTGTTGCAGCGGTCGGT-3' and X153, 5'-GGTTGTGCAACAGTTAATT-3' respectively. They were deduced by use of the PrimerSelect program of DNASTAR, Inc. (Madison, WI).

PCR amplifications were performed with the Advantage genomic PCR kit (Clontech). The kit utilized two thermostable DNA polymerases (Tth DNA polymerase as the primary polymerase and Vent DNA polymerase for $3^{\prime} \rightarrow 5^{\prime}$ proofreading function). Amplification was carried out on $100 \mathrm{ng}$ of highly intact genomic DNA of the snake liver in a reaction mixture $(50 \mu \mathrm{l})$ containing $0.2 \mathrm{~mm}$ dNTPs each, 0.2 umole each of sense and antisense primers, $5 \mu \mathrm{l}$ Tth PCR reaction buffer ( $40 \mathrm{~mm}$ Tris- $\mathrm{HCl}$ at $\mathrm{pH} 9.3$ and $25^{\circ} \mathrm{C}, 15 \mathrm{~mm}$ potassium acetate, $2.2 \mu \mathrm{l}$ of $25 \mathrm{~mm}$ magnesium acetate) and 0.1 unit of Advantage Tth polymerase mixture (Tth polymerase and Tth start antibody). The thermal profile involved a hot start at $94^{\circ} \mathrm{C}$ for $1 \mathrm{~min}$ followed by 30 cycles of $30 \mathrm{sec}$ at $94^{\circ} \mathrm{C}, 30 \mathrm{sec}$ at $50^{\circ} \mathrm{C}$ and $3 \mathrm{~min}$ at $68^{\circ} \mathrm{C}$ and a final extension at $68^{\circ} \mathrm{C}$ for 3 min after the last cycle with a Perkin Elmer Cetus thermal cycler (model 480).

\section{Amplification of $5^{\prime}$ - and $3^{\prime}$-Flanking Regions}

To elucidate the $5^{\prime}$ and $3^{\prime}$ ends of the sequenced NTX gene, Universal GenomeWalker kit (CLONTECH) was used according to the manufacturer's procedure. Briefly, the procedure involved the construction of the adaptor-ligated libraries made by separate restriction digestion of highly intact genomic DNA with DraI, EcoRV, PvuII, ScaI, and StuI followed by purification of the digested fragments and ligation to special adaptors provided in the kit. The adaptor-ligated genomic DNA fragments also known as GenomeWalker libraries were used as templates in DNA walking experiments with the genomic PCR kit (CLONTECH). To map the 5' end of the NTX gene(s), two sets of primers were used: the adaptor primer 1 (AP1), 5'-GTAATACGACTCACTATAGGGC-3', provided in the kit and the gene-specific primer X287, 5'-CCTAAGTCCAGGCACACGATTGTCACC-3', for primary PCR and the nested adaptor primer 2 (AP2), 5'-ACTATAGGGCACGCGTGGT-3', provided in the kit and the nested gene-specific primer X286, 5'-GATTGTCACCACCAGCAAGGTCAGCAG-3' for secondary PCR. Primers used for mapping the $3^{\prime}$ end of NTX gene(s) were AP1 and a gene-specific primer, X285, 5'GAATCGAGAGGGGATGTGGTTGCCC-3', for primary PCR and $A P 2$ provided in the kit and a nested gene-specific primer X284, 5'-GTGGTTGCCCTTCAGTGAAGAAAGGC-3', for secondary PCR.

The amplification technique used was the "touchdown" PCR (Don et al. 1991; Roux 1995), which involved a single annealing/extension temperature that was several degrees higher than the melting temperature of the primers during the initial PCR cycles. This temperature was later reduced to the primers' melting temperature for the remaining PCR cycles. The cycling parameters used for both primary PCR were 10 cycles of $25 \mathrm{sec}$ at $94^{\circ} \mathrm{C}$ and $3 \mathrm{~min}$ at $65^{\circ} \mathrm{C}$ (touchdown) and 30 cycles of $25 \mathrm{sec}$ at $94^{\circ} \mathrm{C}$ and $3 \mathrm{~min}$ at $60^{\circ} \mathrm{C}$, followed by $10 \mathrm{~min}$ at $68^{\circ} \mathrm{C}$ after the final cycle. The cycling parameters for the secondary PCR were 10 cycles of $25 \mathrm{sec}$ at $94^{\circ} \mathrm{C}$ and $3 \mathrm{~min}$ at $68^{\circ} \mathrm{C}$ and 30 cycles of $25 \mathrm{sec}$ at $94^{\circ} \mathrm{C}$ and 3 min at $60^{\circ} \mathrm{C}$ followed by a final extension of $68^{\circ} \mathrm{C}$ for $10 \mathrm{~min}$ after the last cycle.

\section{Subcloning and DNA Sequencing}

The genomic PCR products were analyzed on agarose gels. The appropriate bands were purified (Qiaquick gel extraction kit, Qiagen) and subcloned into pT-Adv vector (Advantage Cloning kit; CLONTECH). The ligated products were then transformed into Escherichia coli strain TOP10F' and the recombinants selected on an LB-Amp $(50 \mu \mathrm{g} / \mathrm{ml})$ plate supplemented with IPTG and X-gal according to Sambrook et al. (1989). Putative recombinant clones were then subjected to Sanger dideoxy DNA sequencing (Sanger et al. 1977), with M13/pUC (Armugam et al. 1997). The inserts were later sequenced on both strands with M13 and sequence-specific, sense, and antisense primers. All double-stranded sequencing was performed with the ABI Prism Dye Terminator Cycle Sequencing Ready Reaction kit (Perkin-Elmer) and an auto- 
mated fluorescent DNA sequencer (Applied Biosystem, model 373).

\section{Sequence Analysis}

Nucleotide sequence homology searches of nonredundant databases of GenBank (National Center for Biotechnology Information) were performed with the BLAST program. DNA sequence alignments were carried out by use of the DNASIS software package from Hitachi Software Engineering.

\section{Southern Hybridization of Genomic DNA}

Genomic DNA was digested with restriction enzymes and the fragments resolved by electrophoresis on $0.8 \%$ agarose gels. The fragments were then blotted onto a nitrocellulose membrane (Schleicher \& Schuell) according to the procedure described by Southern (1975). Amplified PCR fragment of the neurotoxin cDNA was labeled by $\left[\alpha-{ }^{32} \mathrm{P}\right]$ dCTP and random hexamer priming (Megaprime DNA labeling kit; Amersham). DNA hybridization was carried out overnight as described by Sambrook et al. (1989) at $60^{\circ} \mathrm{C}$ with $6 \times$ SSC, $5 \times$ Denhardt's solution, $0.1 \%$ SDS, and $100 \mu \mathrm{g} / \mathrm{ml}$ sonicated and denatured salmon sperm DNA with at least $10^{6} \mathrm{cpm} / \mathrm{ml}{ }^{32} \mathrm{P}$-labeled probes. Blots were washed for $10 \mathrm{~min}$ with $6 \times$ SSC, $20 \mathrm{~min}$ with $2 \times$ SSC containing $0.1 \%$ SDS, 20 min with $1 \times$ SSC $(+0.1 \%$ SDS $)$ once at room temperature and once at $60^{\circ} \mathrm{C}$. Autoradiography was carried out at $-70^{\circ} \mathrm{C}$.

\section{Primer Extension}

Primer extension analysis was performed to identify the TISs of the NTX gene(s). Total cellular RNA was extracted from the N. n. sputatrix venom glands by use of the guanidine isothiocyanate method (Chirgwin et al. 1979), and the integrity of total RNA was analyzed by denaturing formaldehyde agarose electrophoresis (Sambrook et al. 1989). Primer extension analysis was carried out according to the procedure described by Lachumanan et al. (1998) with $\left[\gamma^{-33} \mathrm{P}\right]$ dATP at a specific activity of $>5000 \mathrm{Ci} / \mathrm{mmol}$. The products were electrophoresed on $6 \%$ denaturing polyacrylamide DNA sequencing gels. A set of dideoxynucleotide DNA sequencing reactions with ${ }^{33}$ P-labeled primer X286 and 30 fmoles of the pT-Adv template harboring the 5 '-flanking region of the NTX gene was generated with a AmpliCycle sequencing kit (PerkinElmer) and was used as size markers.

\section{ACKNOWLEDGMENTS}

This work was supported by a research grant RP960324 from the National University of Singapore. F.A. is the recipient of a university scholarship.

The publication costs of this article were defrayed in part by payment of page charges. This article must therefore be hereby marked "advertisement" in accordance with 18 USC section 1734 solely to indicate this fact.

\section{REFERENCES}

Afifiyan, F., A. Armugam, P. Gopalakrishnakone, C.-H. Tan, and K. Jeyaseelan. 1998. Four new postsynaptic neurotoxins from Naja naja sputatrix venom: cDNA cloning, protein expression and phylogenetic analysis. Toxicon 36: 1871-1885.

Akira, S., H. Ishiki, T. Sugita, O. Tanabe, S. Kinoshita, Y. Nishio, T. Nakajima, T. Hirano, and T. Kishimoto. 1990. A nuclear factor for IL-6 expression (NF-IL6) is a member of a C/EBP family. ЕМBO J. 9: 1897-1906.
Armugam, A., L. Earnest, M.C.M. Chung, P. Goplakrishnakone, C.H. Tan, N.H. Tan, and K. Jeyaseelan. 1997. Cloning and characterization of cDNAs encoding three isoforms of phospholipase $\mathrm{A}_{2}$ in Malayan spitting cobra (Naja naja sputatrix) venom. Toxicon 35: 27-37.

Baeuerle, P.A. 1991. The inducible transcription activator NF-kappa B: Regulation by distinct protein subunits. Biochim. Biophys. Acta 1072: 63-80.

Breathnach, R. and P. Chambon. 1981. Organization and expression of eucaryotic split genes coding for proteins. Annu. Rev. Biochem. 50: $349-383$.

Chang, C.C. 1979. The action of snake venom on nerve and muscle. In Snake venoms, handbook of experimental pharmacology, Vol. 52. (ed. C.Y. Lee), pp. 309-376. Springer-Verlag, Berlin, Germany.

Chang, L.S. and E. Hong. 1997. Novel snoRNAs from Naja naja atra (Taiwan cobra) and Bungarus multicinctus (Taiwan Banded Krait), form extended sequence complementarity to $5 \mathrm{~S}$ rRNA. Biochem. Biophys. Res. Commun. 136: 782-784.

Chang, L.S., Y.C. Chou, S.R. Lin, B.N. Wu, J. Lin, E. Hong, Y.J. Sun, and C.D. Hsiao. 1997a. A novel neurotoxin, cobrotoxin b, from Naja naja atra (Taiwan cobra) venom: Purification, characterization and gene organization. J. Biochem. 122: $1253-1259$.

Chang, L.S., J. Lin, Y.C. Chou, and E. Hong. 1997b. Genomic structures of cardiotoxin 4 and cobrotoxin from Naja naja atra (Taiwan cobra). Biochem. Biophys. Res. Commun. 239: 756-762.

Chirgwin, J.M., A.E. Przybyla, R.A. Macdonald, and W.J. Rutter. 1979. Isolation of biologically active ribonucleic acid from sources enriched in ribonuclease. Biochemistry 18: 5294-5299.

Csank, C., F.M. Taylor, and D.W. Martindale. 1990. Nuclear pre-mRNA introns: Analysis and comparison of intron sequences from Tetrahymena thermophila and other eukaryotes. Nucleic Acids Res. 18: 5133-5141.

Dibb, N.J. and A.J. Newman. 1989. Evidence that introns arose at proto-splice sites. EMBO J. 8: 2015-2021.

Don, R.H., P.T. Cox, B.J. Wainwright, K. Baker, and J.S. Mattix. 1991. Touchdown PCR to circumvent spurious priming during gene amplification. Nucleic Acids Res. 19: 4008.

Ducancel, F., G. Gutgnery-Frelat, J.-C. Boulain, and A. Menez. 1990 Nucleotide sequence and structure analysis of cDNAs encoding short-chain neurotoxin from venom glands of a sea snake (Aipysurus laevis). Toxicon 28: 119-123.

Dufton, M.J. and R.C. Hider. 1983. Conformational properties of the neurotoxins and cytotoxins isolated from elapid snake venom. CRC Crit. Rev. Biochem. 14: 113-171.

Faisst, S. and S. Meyer. 1992. Compilation of vertebrate-encoded transcription factors. Nucleic Acids Res. 20: 3-26.

Fuse, N., T. Tsuchiya, Y. Nonomura, A. Menez, and T. Tamiya. 1990. Structure of the short-chain neurotoxin, erabutoxin c, precursor gene. Eur. J. Biochem. 193: 629-633.

Gendeh, G.S., M.C. Chung, and K. Jeyaseelan. 1997. Genomic structure of a potassium channel toxin from Heteractis magnifica. FEBS Lett. 418: $183-188$

Gil, A. and N.J. Proudfoot. 1984. A sequence downstream of AAUAAA is required for rabbit beta-globin mRNA 3 '-end formation. Nature 312: 473-474.

Gilbert, W. 1987. The exon theory of genes. Cold Spring Harbor Symp. Quant. Biol. 52: 901-905.

Iida, Y. and F. Sasaki. 1983. Recognition patterns for exon-intron junctions in higher organisms as revealed by a computer search. J. Biochem. 94: 1731-1738.

Imagawa, M., R. Chiu, and M. Karin. 1987. Transcription factor AP-2 mediates induction by two different signal-transduction pathways: Protein kinase C and cAMP. Cell 51: 251-260.

Imagawa S., T. Izumi, and Y. Miura. 1994. Positive and negative regulation of erythropoietin gene. J. Biol. Chem. 269: 9038-9044.

Kozak, M. 1986. Bifunctional messenger RNAs in eukaryotes. Cell 44: $283-292$

1987. An analysis of 5'-noncoding sequences from 699 vertebrate messenger RNAs. Nucleic Acids Res. 15: 8125-8132. 
1991. Effects of long 5' leader sequences on initiation by eukaryotic ribosomes in vitro. Gene Expr. 1: 117-125.

Latchman, D. S. 1991. Eukaryotic transcription factors. Academic Press, London, UK.

Latchumanan, R., A. Armugam, C-H. Tan, and K. Jeyaseelan. 1998. Structure and organization of the polymorphic cardiotoxin gene in Naja naja sputatrix. FEBS Lett. 433: 119-124.

Low, B.W., H.S. Preston, A. Sato, L.S. Rosen, J.E. Searl, A.D. Rudko, and J.R. Richardson. 1976. Three dimensional structure of erabutoxin b neurotoxic protein: Inhibitor of acetylcholine receptor. Proc. Natl. Acad. Sci. 73: 2991-2994.

Maxwell, E.S. and M.J. Fournier. 1995. The small nuclear RNAs. Annu. Rev. Biochem. 35: 897-934.

McLauchlan, J., D. Gaffney, J.L. Whitton, and J.B. Clements. 1985. The consensus sequence YGTGTTYY located downstream from the AATAAA signal is required for efficient formation of mRNA 3' termini. Nucleic Acids Res. 13: 1347-1368.

Moura-da-Silva, A.M., M.J.I. Paine, M.R.V. Diniz, R.D.G. Theakston, and J.M. Crampton. 1995. The molecular cloning of a phospholipase $\mathrm{A}_{2}$ from Bothrops jararacussu venom: Evolution of venom group II phospholipase $\mathrm{A}_{2}$ 's may imply gene duplication. J. Mol. Evol. 41: 174-179.

Nakashima, K.-I., T. Ogawa, N. Oda, M. Hattori, Y. Sakaki, H. Kihara, and M. Ohno. 1993. Accelerated evolution of Trimeresurus flavoviridis venom gland phospholipase $\mathrm{A}_{2}$ isosyme. Proc. Natl. Acad. Sci. 90: 5964-5968.

Nakashima, K.-I., I. Nobuhisa, M. Deshimaru, M. Nakai, T. Ogawa, Y. Shimohigashi, Y. Fukumaki, M. Hattori, Y. Sakaki, M. Hattoti., and M. Ohno. 1995. Accelerated evolution in the protein-coding regions is universal in crotalinae snake venom gland phospholipase A2 isozyme genes. Proc. Natl. Acad. Sci. 92: 5605-5609.

Obara, K., N. Fuse, T. Tsuchiye, T. Nonomura, A. Menez, and T. Tamiya. 1989. Sequence analysis of a cDNA encoding erabutoxin b from the sea-snake Laticauda semifasciata. Nucleic Acids Res. 17: 10490.

Ohno, M., R. Menez, T. Ogawa, J.M. Danse, Y. Shimohigashi, C. Formen, F. Ducancel, S. Zinn-Juxin, M.H. Ledu, J.C. Boulain, T. Tamiya, and A. Menez. 1998. Molecular evolution of snake toxins: Is the functional diversity of snake toxins associated with a mechanism of accelerated evolution? Prog. Nucleic Acid Res. Mol. Biol. 59: 307-364.
Orgel, L. and F.H.C. Crick. 1980. Selfish DNA; the ultimate parasite. Nature 284: 604-607.

Postel, E.H., S.J. Berberich, and C.A. Ferrone. 1993. Human c-myc transcription factor PuF identified as nm23-H2 nucleoside diphosphate kinase, a candidate suppressor of tumor metastasis. Science 261: 478-480.

Rogers, J.H. 1989. How were introns inserted into nuclear genes? Trends Genet. 5: 213-216.

Roux, K.H. 1995. Optimization and troubleshooting in PCR. PCR Methods Applic. 4: 5185-5194.

Sambrook, J., E.F. Fritsch, and T. Maniatis. 1989. Molecular cloning: $A$ laboratory manual. Cold Spring Harbor Laboratory Press, Cold Spring Harbor, NY.

Sanger, F., S. Nicklen, and A.R. Coulson. 1977. DNA sequencing with chain-terminating inhibitors. Proc. Natl. Acad. Sci. 74: $5463-5467$.

Southern, E.M. 1975. Detection of specific sequences among DNA fragments separated by gel electrophoresis. J. Mol. Biol. 98: 503-517.

Tamiya, T., A. Lamouroux, J.-F. Julien, B. Grima, J. Mallet, P. Fromageot, and A. Menez. 1985. Cloning and sequence analysis of the cDNA encoding a snake neurotoxin precursor. Biochimie 67: 185-189.

Tamiya, T., N. Fuse, N. Takakura, A. Menez, and T. Tsuchiya. 1992. Gene structure of the snake-short chain neurotoxin precursor. In Recent advances in toxinology research (ed. P. Gopalakrishnakone), Vol. 1, pp 182-195. Venom and Toxin Research Group, National University of Singapore, Singapore.

Tan, N H. 1982. Cardiotoxins from the venom of Malayan cobra (Naja naja sputatrix) Arch. Biochem. Biophys. 218: 51-58.

- 1983. Isolation and characterization of two toxins from the venom of the Malayan cobra (Naja naja sputatrix). Toxicon 21: 201-207.

- 1992. The biochemistry of venomous snakes of Malaysia-a review. Trop. Biomed. 8: 91-103.

Tsernoglou, D., and G.A. Petsko. 1976. The crystal structure of neurotoxin from sea snake at 2.2A resolution. FEBS Lett. 68: $1-4$.

Received November 2, 1998; accepted in revised form January 19, 1999.

\section{Genome Research}




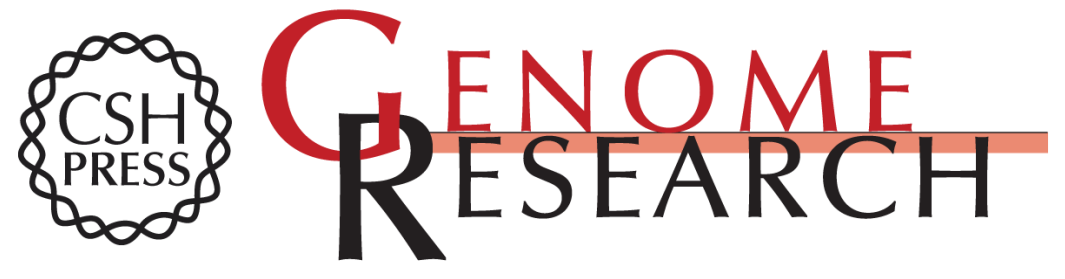

\section{Postsynaptic $\alpha$-Neurotoxin Gene of the Spitting Cobra, Naja naja sputatrix : Structure, Organization, and Phylogenetic Analysis}

Fatemeh Afifiyan, Arunmoziarasi Armugam, Chee Hong Tan, et al.

Genome Res. 1999 9: 259-266

Access the most recent version at doi:10.1101/gr.9.3.259

References This article cites 44 articles, 7 of which can be accessed free at:

http://genome.cshlp.org/content/9/3/259.full.html\#ref-list-1

\section{License}

Email Alerting Receive free email alerts when new articles cite this article - sign up in the box at the Service top right corner of the article or click here.

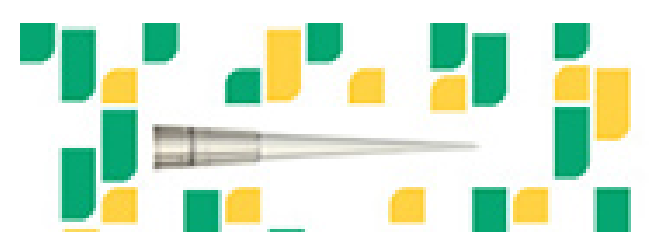

To subscribe to Genome Research go to: https://genome.cshlp.org/subscriptions 